\title{
Development and implementation cost analysis of telephone- and Internet-based interventions for the maintenance of weight loss
}

Richard T. Meenan, PhD, MPH, MBA, Victor J. Stevens, PhD, Kristine Funk, MS, RD, Alan Bauck, BS, Gerald J. Jerome, PhD, Lillian F. Lien, MD, Lawrence Appel, MD, MPH, Jack F. Hollis, PhD, Phillip L. Brantley, PhD, and Laura P. Svetkey, MD

\section{Abstract}

Objectives-The Weight Loss Maintenance Trial (WLM) was a multi-center, randomized trial comparing two weight loss maintenance interventions, a personal contact program (PC) with primarily telephone-based monthly contacts, and an Internet-based program (IT), to a self-directed control group, among overweight or obese individuals at high cardiovascular risk. This paper describes implementation costs of both interventions as well as IT development costs.

Methods-Resources were micro-costed in 2006 dollars from the primary perspective of a sponsoring healthcare system considering adopting an extant intervention, rather than developing its own. Costs were discounted at 3\% annually. Length of trial participation was 30 months (randomization during February-November 2004). IT development costs were assessed over 36 months. Univariate and multivariate, including probabilistic, sensitivity analyses were performed.

Results-Total discounted IT development costs over 36 months were $\$ 839,949$ ( $\$ 2,414$ per IT participant). Discounted 30-month implementation costs for $342 \mathrm{PC}$ participants were $\$ 537,242$ (\$1,571 per participant), and for 348 IT participants, were $\$ 214,879$ (\$617 per participant). Under all plausible scenarios, PC implementation costs exceeded IT implementation costs.

Conclusions-Costs of implementing and operating an Internet-based intervention for weight loss maintenance were substantially less than analogous costs of an intervention using standard phone and in-person contacts, and are of a magnitude that would be attractive to many health systems, subject to demonstration of cost-effectiveness.

\section{Keywords}

Cost; weight loss; Internet; behavioral intervention; implementation

\section{INTRODUCTION}

Together, the phenomenon of overweight and obesity is the second leading cause of preventable death in the US, and has increased dramatically over the last 20 years $(8,9)$. Excess weight contributes to cardiovascular disease (CVD) risk factors and ultimately to CVD itself. Although behavioral weight loss interventions consistently demonstrate shortterm success, longer-term weight re-gain is common (15). A critical factor for sustained weight loss is continued intervention with frequent contacts $(7 ; 15)$. The Weight Loss Maintenance Trial (WLM) was a multi-center, randomized, controlled trial comparing the effects of two maintenance interventions to a self-directed control group, among overweight

Corresponding Author: Richard T. Meenan, PhD, MPH, MBA Center for Health Research, Kaiser Permanente Northwest 3800 N. Interstate Ave. Portland, OR 97227 USA Phone: 503-335-2484 Fax: 503-335-2424 richard.meenan @kpchr.org. 
or obese individuals at high CVD risk. Both the Personal Contact condition, a program of monthly contacts with a trained interventionist, and the Internet-based condition, a sophisticated interactive program, were designed to maintain frequent contacts compared to usual care.

This paper describes and compares the implementation costs of the WLM interventions. We also estimate the development costs of the Internet-based intervention. Understanding better the costs of implementing and operating these programs will help analysts conducting economic evaluations of similar weight loss and other lifestyle change programs. It will also facilitate feasibility studies of their dissemination, if they should eventually prove costeffective.

\section{TRIAL DESCRIPTION}

The WLM trial was a four-center randomized trial comparing two alternative strategies for maintaining long-term weight loss among 1,032 overweight and obese (body mass index = $25-45 \mathrm{~kg} / \mathrm{m}^{2}$ ) persons on medication for hypertension and/or dyslipidemia. Four clinical centers participated—Duke University (Durham, North Carolina), Johns Hopkins University (Baltimore, Maryland), Pennington Biomedical Research Center (Baton Rouge, Louisiana), and the Kaiser Permanente Center for Health Research (Portland, Oregon). During Phase I, 1,685 participants started an intensive weight loss intervention of 20 weekly group sessions over six months. Lifestyle interventions focused on behavioral strategies for implementing increased physical activity and reduced calorie intake in the context of a healthy diet (i.e., the Dietary Approaches to Stop Hypertension diet [DASH]). Phase I enrollment occurred between August 2003 and July 2004.

Phase I participants who lost $>4 \mathrm{~kg}$ were eligible for Phase II, and were randomized between February 2004 and December 2004 to one of three weight loss maintenance interventions: 1) Personal Contact (PC) included monthly contact with an interventionist by telephone or in person; 2) Interactive Technology (IT) featured unlimited access to an interactive website that provided ongoing web-based support; and 3) a Self-Directed (SD) control condition. Follow-up weight and other data were measured at six-month intervals through 30 months of Phase II (i.e., 36 months from the beginning of Phase I). Final data collection ended in June 2007.

The primary outcome was weight change from the end of Phase I to the end of Phase II (30 months post-randomization). Other outcomes included subgroup weight change, control and prevalence of CVD risk factors, and behavior change measures. A detailed trial design description has been published (2), and is summarized below.

\section{Personal Contact (PC)}

Study interventionists contacted PC participants monthly over the 30-month intervention period; annually, nine contacts were phone-based, supplemented by three face-to-face (FTF) contacts. PC contacts included reinforcement of calorie intake to maintain weight loss, a weekly physical activity goal of 225 minutes, and consumption of the DASH diet.

FTF contacts were approximately 45 minutes and had three components. Check-in (10-15 min.) included a weigh-in, review of self-monitoring and participant goals, and feedback on last month's performance. Discussion and Training (20-30 min.) consisted of brief topical discussions or hands-on training, involving methods for handling high-risk situations and possible lapses in diet and activity plans. FTF sessions focused on problem solving and relapse-prevention strategies in which interventionists were extensively trained, and which were also practiced in phone sessions described below. In Action Planning (5-10 min.), 
interventionists used motivational interviewing techniques and strategies to assist participants with identifying short-term diet and activity goals.

Phone contacts lasted 10-15 minutes. Standardized materials and procedures guided the topical discussion, and documented it for use in future calls. Interventionists established rapport, reviewed the previous month's diet and activity efforts, and recorded selfmonitoring and physical activity data. Identified barriers or difficulties were discussed and problem-solving techniques agreed upon. Interventionists used case scenarios as examples when identifying common situations, barriers, and problem-solving approaches. Scenarios also triggered questions and supportive comments.

Various techniques were used to ensure completion of one-on-one contacts. All calls were prescheduled. Subsequent calls were scheduled during the current call. Daily phone logs were generated for each interventionist with call schedules and contact data; logs were also used to verify call completion and for rescheduling. A contact information database was continuously updated. Participants were contacted within 24 hours to reschedule missed calls; rescheduling efforts were tracked for early problem identification. A case conference mechanism helped interventionists with difficult situations and to develop approaches to nonadherence.

\section{Interactive Technology (IT)}

Core behavior-change components of the IT intervention were similar to those of $\mathrm{PC}$, but used Internet and automated phone technology to enhance feedback frequency and timeliness. Website features included weekly weight loss tips, a personal profile, links to reliable health and weight loss-related information, and printable materials (12).

Figure 1 is an overview of IT's content and process. Core elements included strategies to promote adherence to health behaviors for weight loss maintenance. After initial FTF orientation with an interventionist, participants used the website to construct a personal action plan that could be updated at any time. Collaborative goal setting and problemsolving techniques were used to identify action plans for perceived barriers and triggers. Tailored e-mail reminders, with a backup interactive voice response (IVR) phone system, prompted participants to visit the website for self-monitoring and motivational modules. Participants could also log on at any time to enter data on weight, food records, and physical activity, communicate with other participants through a monitored bulletin board for social support, or seek other information. Feedback reports were available on demand, tracking participants' weight, dietary pattern, and physical activity over time.

\section{Trial Results}

Primary trial outcomes have recently been published (13). Thirty-month follow-up rates were 93\% for IT (323 of 348) and 94\% for PC (321 of 342). One death occurred in each group during the study; most others were losses to follow-up. Mean Phase I weight loss was $8.5 \mathrm{~kg}$, although weight regain occurred after randomization. Both interventions produced improved weight loss maintenance over SD during the first 24 months following randomization (IT: mean $-0.9 \mathrm{~kg}$ difference in weight change, $\mathrm{p}=.045$; PC: mean $-2.0 \mathrm{~kg}$ difference in weight change, $\mathrm{p}<.001$ ). However, only the PC intervention showed a statistically significant improvement over SD at 30 months (PC: mean $-1.5 \mathrm{~kg}$ difference in weight change, $p<.001)$. Overall, $71 \%$ of study participants remained below entry weight at 30 months. 


\section{METHODS}

We define intervention costs as the value of resources used to implement and operate the subject interventions over the 30-month trial period, and measure them from the perspective of a sponsoring healthcare system. Costs exclude participant investments of time, money, or other resources. SD participants received no intervention components.

The primary analysis is limited to implementation costs, and is not a true economic evaluation comparing the costs and consequences of alternative courses of action (11). Research-related costs not integral to the intervention are excluded. The primary analysis also excludes development costs; the analytic perspective is a healthcare system considering adopting an extant intervention, rather than developing its own. We did not analyze the cost of developing PC, which is conventional with well understood development activities. For WLM, much of PC was adapted from the earlier PREMIER weight loss trial $(1 ; 3)$. In contrast, few previous studies used websites similar to WLM's IT intervention, designed specifically to support long-term weight loss maintenance $(4-6 ; 14 ; 16)$. To our knowledge, none estimated the costs of such an intervention. Therefore, in a later section we present estimated IT development costs. We also assume that the website is (developed and) implemented by an organization with significant resources for and experience in healthcarerelated website delivery. This implies multiple web-based projects jointly share most equipment and non-labor resources.

Project staff identified relevant cost components, classified as labor or non-labor. When possible, intervention components were micro-costed - participant-level data were collected on the exact number and type of each resource. Project-specific unit costs were applied to quantities consumed, and the results summed to obtain resource values. For example, intervention staff time was valued as the total intervention time of each staff member multiplied by the appropriate wage rate, including fringe benefits and a $30 \%$ "support rate" multiplier that accounts for non-fringe activities (e.g., department meetings, daily breaks) not reasonably assignable to one project. (A project site uses the $30 \%$ figure in budgeting.) Other costs included equipment or printed materials. Cost data were collected from project staff, IT staff, finance department staff, expense reports, or retrospective labor estimates. We applied Portland, Oregon-based unit costs-e.g., wage rates - to quantities, but tested a wide range of costs in sensitivity analyses. For each intervention, total cost and cost per participant were estimated. All costs were in 2006 dollars using the Prospective Payment System Input Price Index (10). Costs were discounted at a 3\% annual rate. Univariate and multivariate sensitivity analyses addressed cost variation between different implementation settings. We also performed a Monte Carlo simulation in DataPro (TreeAge Software, Inc.); parameter-specific distributions were resampled and analytic results recalculated 10,000 times, with the intent to produce an empirical distribution of model results.

\section{Inputs: Personal Contact}

Face-to-face visits-Costs include counseling time (plus administration and multiple reminder call attempts), facility space, phone charges, standard printed materials (discussion guides and case scenarios), and supplies.

Telephone contacts-Costs include counseling time (plus administration and multiple contact attempts), daily phone logs and other materials, phone charges, case conference mechanism, and supplies.

Annual training session-Costs include trainer and trainee time (plus administration), printed materials, and a rental facility fee. Travel time is excluded because on-site training is assumed. 
Quality control—Costs include an intervention director's oversight activities, and a case conference mechanism to periodically review problem cases for assistance with modifying an action plan.

\section{Inputs: Interactive Technology (implementation)}

IT-Specific Infrastructure-We distinguish between general fixed overhead charges that are assumed common to both interventions (e.g., utilities, janitorial), and IT-specific infrastructure. The latter resources—enhanced air conditioning, uninterruptible power supply, generator, network backbone, Ethernet switches, router, firewall, and Internet connectivity - refer to particular networking, security, and other resources needed to operate an enterprise capable of hosting a website, but which are unnecessary for a PC-type intervention.

Direct Labor-A content developer/maintainer assured that website content was current, complete, and "on message."

A system architect organized and oversaw website structure, based on user needs and cost and scheduling constraints.

An application developer converted design instructions from the system architect into program code.

A primary contact person provided website user support by phone and/or e-mail.

A product manager provided project coordination and oversight.

\section{Direct Non-Labor}

Hardware: A collection of three web farm servers was maintained to meet needs beyond any one server. Web farms often allocate primary and backup servers to a single task.

Two backup servers provided redundancy.

A Structured Query Language ( $S Q L)$ database server provided searchable information retrieval and data warehousing.

An $S Q L$ reporting server provided interactive and printed reports.

Two domain control servers responded to security authentication requests.

Software: An $S Q L$ server functioned as a relational database management system.

Email control software organized website email components, e.g., authentication, file attachments, embedded images.

Two enterprise-level server platforms, designed for high-volume, high-traffic networks, provided basic functionalities of the server hardware.

Contracted Services: Internet service provider charges were monthly fees paid for a more user-friendly website address than the hosting site's default address.

Data backup charges provided disaster recovery and data retrieval operations.

Two years of IVR extended support represented ongoing maintenance of IVR hardware and software. 


\section{Inputs: Interactive Technology (development)}

Direct Labor-The second category of website design involves a clearly communicated stepwise outline of the standardized development pathway each interactive module follows. The design team organized the IT development process by task: needs assessment, content development, design specification, graphic design, usability testing, programming, quality assurance, pilot testing, and project management. Because most IT-based personnel performed multiple functions during development, it is more informative to categorize IT development labor costs by function than to categorize them by individual.

\section{Direct Non-Labor}

Hardware: Developer workstations were high-performance computers used for graphics, computer-assisted design, software development, and scientific applications.

Servers were computer systems that provide services to other computer systems (clients) over a network. "Server" refers to hardware—a computer system, or software-SQL server.

A development/staging server temporarily staged new or revised Web pages before they were made live.

An e-mail server was used as messaging and collaborative software including electronic mail, shared calendars and tasks, and support for mobile and web-based information access, supporting very large data storage.

Software: Various software components, requiring an underlying productivity suite such as Microsoft Office, were also used. Diagramming software produced graphical diagrams.

Source control software managed multiple revisions of the same information unit, such as a computer program.

An integrated suite of applications was used in graphic design.

An $S Q L$ server managed the overall relational database.

An integrated software development program provided comprehensive facilities to web programmers during development to maximize productivity.

Email control software organized website email components, e.g., authentication, file attachments, embedded images.

A (standard) server platform provided basic functionalities of the server hardware.

$A$ web server accepted information requests from clients (web browsers), and served them formatted responses along with optional data contents, usually web pages, including documents and linked objects (images, etc.).

An oversight program provided pre-coded solutions to common program needs, and managed specific program execution.

Additional Services: Internet service provider charges.

Data backup services.

Months 31-36 of IT-specific infrastructure were also included. 


\section{Interactive Voice Response (IVR)}

Direct Labor: Script and algorithm design involved developing participant contact language and a response flow chart.

Programming labor converted design instructions into program code.

Testing labor provided oversight of pilot testing.

IVR technical support was the primary contact for technical/operational questions.

Direct Non-Labor: Total IVR system installation cost included the server, data modem, dual telephony board, text-to-speech software, system software, training, licenses, and 1-year warranty.

Two years of IVR extended support represented ongoing maintenance of IVR hardware and software.

\section{RESULTS}

Supplemental Table 1 lists component baseline costs for PC and Table 1 lists total estimated implementation costs. Total discounted 30-month implementation costs for the $342 \mathrm{PC}$ participants were $\$ 537,242$ (per-participant costs: $\$ 1,571$ total; $\$ 628$ annual). Nearly all costs were labor, about half of which could be classified as variable, driven by the number of participants. Most fixed costs arose from the intervention director's 0.70 full-time equivalent allocation.

Supplemental Table 2 lists baseline IT implementation parameter values, and Table 2 summarizes estimated IT implementation costs. Total estimated 30-month implementation costs were $\$ 214,879$ (per-participant costs: $\$ 617$ total; $\$ 247$ annual). Labor represented $90 \%$ of total costs; note that user support absorbed $33 \%$ of total labor expense (30\% of total expense). WLM adopted a tiered approach to website user support; support staff fielded initial inquiries with more complex inquiries referred to the product manager, and as appropriate, to the web programmer. Because website contact was largely patient-initiated, we believe that no labor expense would be considered variable (in the sense of varying with the number of participants). In particular, WLM staff believe that IT user support could accommodate double or even triple the number of participants without difficulty. Three percent of total costs were attributed to IT-specific infrastructure.

\section{Sensitivity Analyses}

In univariate sensitivity analyses, no reasonable change in parameter values would lower the estimated 30-month implementation cost of PC below $\$ 400,000$. Even assuming both an FTF counselor hourly wage of $\$ 25$ and a 30-minute FTF session together lowered total cost only to $\$ 406,000$. Increasing the allocation percentage for IT-specific infrastructure from $1 \%$ to $50 \%$ raised total IT implementation cost to $\$ 339,000$. The probabilistic analysis was simply confirmatory; IT was cheaper to implement in virtually all iterations (parameter distributions and results available upon request).

\section{Website Development Costs}

For illustrative purposes, we estimated the 36-month costs of developing the IT website. Supplemental Table 3 lists baseline development parameter values, and Table 3 lists estimated IT development costs. As mentioned earlier, we present labor expenses by 
function because most personnel performed multiple roles. Non-labor expenses are predominantly hardware (e.g., various servers) and software (e.g., version control).

Total discounted development costs were $\$ 839,949$ (per-participant costs: $\$ 2,414$ total; $\$ 805$ annual). Website labor represented $85 \%$ of total costs; the largest proportions of labor expense were in programming (36\%), project management (17\%), content development $(15 \%)$, and design specification (15\%). One percent of total costs were attributed to ITspecific infrastructure. We included IVR installation $(\$ 90,000)$ in development costs.

Summing development and implementation costs across 66 months (36 development +30 implementation), total discounted IT costs were $\$ 1,045,197$ (per-participant costs: $\$ 3,003$ total; \$546 annual). Although not surprisingly, total IT development and implementation costs exceeded PC implementation costs alone, it is interesting to note that the annual perparticipant cost of IT development and implementation (\$546) was 13\% less than the analogous cost under PC implementation (\$628). Also, we conservatively assumed that development and implementation were completely distinct periods, while in reality these activities may overlap in time, shortening the total measurement period. For WLM, implementation began early in year three of development, which would shorten the total period from 66 to 54 months (5.5 to 4.5 years).

\section{DISCUSSION}

The effect of both interventions was admittedly modest (12), and may not currently justify their implementation. However, research into effective strategies for maintaining long-term weight loss is in its infancy, and the WLM strategies are in early development. As more effective treatment modalities are designed, their implementation will become increasingly feasible, and our analysis lays the groundwork for appropriate cost accounting.

It is perhaps unsurprising that the average per-participant cost of IT implementation was substantially lower (\$954) than that of PC implementation. Note that this difference would accommodate considerable tailoring of an existing website to local circumstances. Also, from the health system perspective, at 348 participants the IT program would seem to operate in the range of the average long-run cost curve exhibiting economies of scale, i.e., the average cost of production declines as output increases. This has practical significance because as we discuss below, implementing health systems are likely to have much larger participant populations than that of the WLM trial. (Note, however, output here is number of participants, not quality-adjusted life-years or other health outcomes. Also, from a societal perspective a higher proportion of costs would be variable because of the value of participant time.) We assumed most costs were fixed, and the marginal cost of an additional website user approached zero. In an operation such as WLM's host location, the benefit of sharing costs across multiple participants is amplified by sharing joint resources across multiple projects, driving average costs even lower.

It is important, however, to distinguish between economies of scale and scalability, an important dimension of website development and operation. In contrast to economies of scale (declining average cost), scalability, strictly speaking, refers to roughly constant average cost-throughput increases proportionately with increases in inputs. The concepts are closely related, but qualitatively scalability is meant to convey the ease with which, say, a new location could be added to the website infrastructure.

How many users could reasonably be added before technical constraints would likely arise? The existing system that hosted the WLM website (i.e., with resource redundancy and other "competing" websites) supported 348 trial participants over 30 months. Some extant webrelated projects at the host site have up to $5 \%$ of their populations using the project website 
concurrently; in WLM, however, concurrent use was typically just one or two participants (again, of 348).

Host site engineers estimate the theoretical maximum of the site's hardware (e.g., servers) is 350,000 participants. This assumes that all excess capacity is devoted to the WLM IT website, and assumes no growth in other websites sharing the resources. However, mild performance degradations - e.g., slower response time, sporadic signal drops—would begin to emerge as early as approximately 3,500 participants, a much smaller number (although ten times the WLM population, and a more representative estimate of an implementing health system in the real world). Around 3,500 participants, average participant cost would decline to approximately $\$ 65$ because few modifications would be needed $(\approx \$ 100$ at 2,300 participants). The first likely constraint is bandwidth, the rate of data transfer supported by a network, usually measured in bytes per second. Without expanded bandwidth, increased website traffic would eventually induce less responsiveness and more frequent service interruptions. Specific project needs can also induce lower performance. WLM, for example, had more complex reporting requirements than many other websites at the host site; this can degrade performance of the associated reporting software.

Software modifications can roughly optimize performance; however, limitations of these modifications would greatly reduce the true maximum number of users under the current system to about 30,000 (again, assuming that true concurrent users represent no more than roughly $5 \%$ ). The cost of software modifications in acquisitions and maintenance can vary widely, but $\$ 150,000$ over 30 months is a reasonable estimate. In this case, average 30month participant cost declines still further to $\$ 12-\$ 15$ ( $\approx \$ 50$ at 7,500 participants). At approximately 30,000 participants and the large theoretical hardware capacity notwithstanding, service would degrade sufficiently that further software modifications would be inadequate, and one or more new servers would be required to expand capacity, while maintaining service quality. Of course, these limits would be reached much more quickly if the host site were already near capacity. Even doubling capacity, however, at participant levels of 100,000 and above, would still result in average 30-month participant cost of $\$ 10-\$ 15$. The clear implication is that cost is unlikely to significantly inhibit implementation of Web-based programs for weight loss maintenance for most health systems, if their effectiveness is established.

\section{CONCLUSION}

When hosted in a facility with substantial resources devoted to and expertise in website delivery, costs of implementing a Web-based intervention for weight loss maintenance are substantially less than those of a conventional program using phone and in-person contacts. In this situation, the per-participant website cost remains less than the personal contact intervention, even including development costs. If future trials demonstrate the effectiveness of these or similar interventions in maintaining initial weight loss, our results can inform the economic evaluations that will assess the true value for money produced by their implementation.

\section{Supplementary Material}

Refer to Web version on PubMed Central for supplementary material.

\section{Acknowledgments}

We thank Shane Albright, John Hall, Fran Heinith, Shannon Leitch, and Michael Thornton at the Kaiser Permanente Center for Health Research for important contributions. Grants 5-U01 HL68734, 5-U01 HL68676, 5- 
U01 HL68790, 5-U01 HL68920, and 5-HL68955 from the National Heart, Lung, and Blood Institute supported this study.

\section{REFERENCES}

1. Appel LJ, Champagne CM, Cooper LS, et al. Effects of comprehensive lifestyle modification on blood pressure control: Main results of the PREMIER clinical trial. JAMA. 2003; 289:2083-2093. [PubMed: 12709466]

2. Brantley PJ, Appel LJ, Hollis JF, et al. Weight Loss Maintenance (WLM): Design and rationale of a multi-center trial to sustain weight loss. Clin Trials. 2008; 5:546-556. [PubMed: 18827047]

3. Funk KL, Elmer PJ, Stevens VJ, et al. PREMIER - A trial of lifestyle interventions for blood pressure control: intervention design and rationale. Health Promot Pract. 2008; 9:271-280. [PubMed: 16803935]

4. Glasgow RE, Nelson CC, Kearney KA, et al. Reach, engagement, and retention in an Internet-based weight loss program in a multi-site randomized controlled trial. J Med Internet Res. 2007; 9:e11. [PubMed: 17513282]

5. Harvey-Berino J, Pintauro S, Buzzell P, et al. Effect of internet support on the long-term maintenance of weight loss. Obes Res. 2004; 12:320-329. [PubMed: 14981225]

6. Harvey-Berino J, Pintauro SJ, Gold EC. The feasibility of using Internet support for the maintenance of weight loss. Behav Modif. 2002; 26:103-116. [PubMed: 11799651]

7. Jeffery RW, Drewnowski A, Epstein LH, et al. Longterm maintenance of weight loss: current status. Health Psychol. 2000; 19(suppl):5-16. [PubMed: 10709944]

8. Ogden CL, Carroll MD, Curtin LR, et al. Prevalence of overweight and obesity in the United States, 1999-2004. JAMA. 2006; 958:1549-1555. [PubMed: 16595758]

9. Overweight and Obesity. U.S. Department of Health and Human Services, Centers for Disease Control and Prevention; Atlanta: Available online: www.cdc.gov/nccdphp/dnpa/obesity/ [Accessed August 29, 2008]

10. Quarterly Index Levels in the CMS Prospective Payment System Input Price Index. Centers for Medicare \& Medicaid Services; Washington, DC: 2007.

11. Shiell A, Donaldson C, Mitton C, et al. Health economic evaluation. J Epidemiol Community Health. 2002; 56:85-88. [PubMed: 11812804]

12. Stevens VJ, Funk KL, Brantley PJ, et al. Design and implementation of an interactive website to support long-term maintenance of weight loss. J Med Internet Res. 2008; 10:e1. [PubMed: 18244892]

13. Svetkey LP, Stevens VJ, Brantley JP, et al. Comparison of strategies for sustaining weight loss: the Weight Loss Maintenance randomized controlled trial. JAMA. 2008; 299:1139-1148. [PubMed: 18334689]

14. Tate DF, Jackvony EH, Wing RR. Effects of Internet behavioral counseling on weight loss in adults at risk for type 2 diabetes: a randomized trial. JAMA. 2003; 289:1833-1836. [PubMed: 12684363]

15. Wadden TA, Crerand CE, Brock J. Behavioral treatment of obesity. Psychiatr Clin North Am. 2005; 28:151-170. [PubMed: 15733617]

16. Wing RR, Tate DF, Gorin AA, et al. A self-regulation program for maintenance of weight loss. NEJM. 2006; 355:1563-1571. [PubMed: 17035649] 


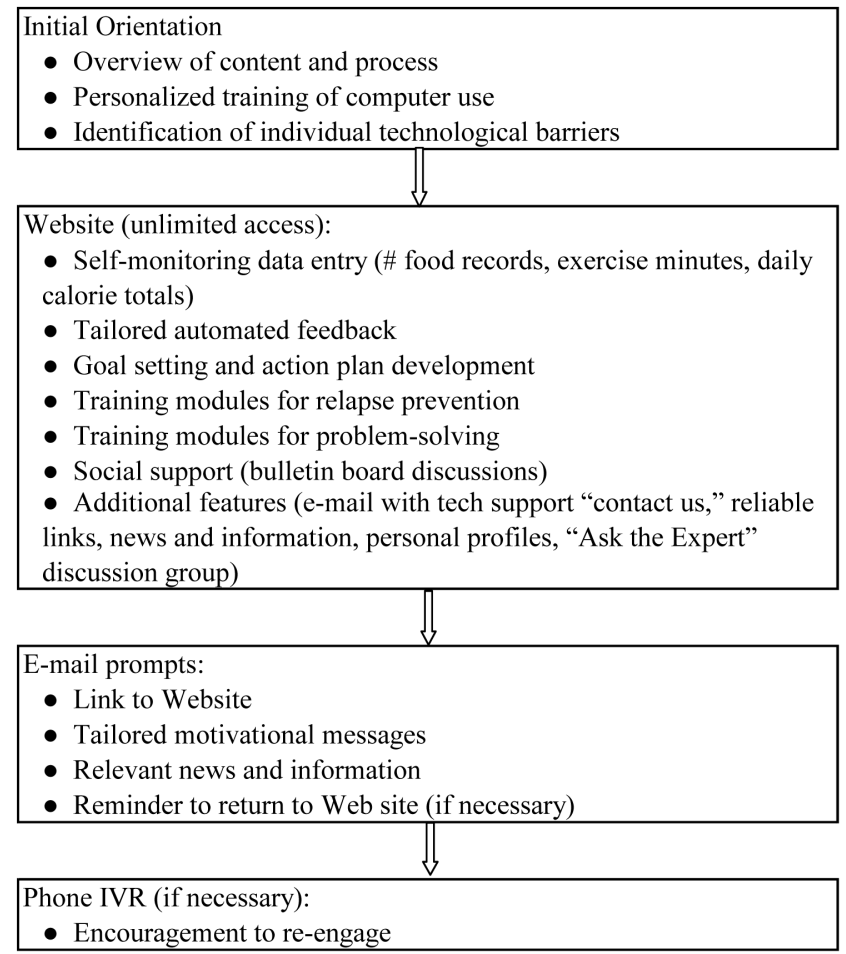

Figure 1. 
Table 1

PC Intervention: Baseline costs (30 months)--Implementation

\begin{tabular}{|c|c|c|}
\hline LABOR & & \\
\hline \multicolumn{3}{|l|}{ Face-to-face visits } \\
\hline Counseling time & $\$ 122,975$ & \\
\hline Administrative time & 40,992 & \\
\hline \multirow[t]{2}{*}{ Reminder phone calls } & 2,733 & \\
\hline & & $\$ 166,699$ \\
\hline \multicolumn{3}{|l|}{ Telephone counseling } \\
\hline Contact attempts & $\$ 16,397$ & \\
\hline Counseling time & 122,975 & \\
\hline \multirow[t]{2}{*}{ Administrative time } & 24,595 & \\
\hline & & $\$ 163,966$ \\
\hline \multicolumn{3}{|l|}{ Annual training } \\
\hline Trainer time & $\$ 6,000$ & \\
\hline \multirow[t]{2}{*}{ Trainee time } & 28,323 & \\
\hline & & $\$ 34,323$ \\
\hline \multicolumn{3}{|l|}{ Quality control } \\
\hline Case conferences & $\$ 8,409$ & \\
\hline \multirow[t]{3}{*}{ Intervention director } & 178,989 & \\
\hline & & $\$ 187,397$ \\
\hline & Total Labor & $\$ 552,386$ \\
\hline \multicolumn{3}{|l|}{ NON-LABOR } \\
\hline \multicolumn{3}{|l|}{ Face-to-face visit(s) } \\
\hline \multirow[t]{2}{*}{ Materials } & $\$ 2,565$ & \\
\hline & & $\$ 2,565$ \\
\hline \multicolumn{3}{|l|}{ Annual training } \\
\hline Materials & $\$ 360$ & \\
\hline \multirow[t]{3}{*}{ Facility fee } & 3,000 & \\
\hline & & $\$ 3,360$ \\
\hline & Total Non-Labor & $\$ 5,925$ \\
\hline \multirow[t]{3}{*}{ Undiscounted } & Total & $\$ 558,311$ \\
\hline & Per Participant & $\$ 1,632$ \\
\hline & Annual Per Participant & $\$ 653$ \\
\hline \multirow[t]{3}{*}{ Discounted at $3 \%$ annually } & Total & $\$ 537,242$ \\
\hline & Per Participant & $\$ 1,571$ \\
\hline & Annual Per Participant & $\$ 628$ \\
\hline
\end{tabular}


Table 2

IT Intervention: Baseline costs (30 months)--Implementation

\begin{tabular}{|c|c|c|}
\hline \multicolumn{3}{|c|}{ INFRASTRUCTURE (hardware +30 months of software maintenance) ${ }^{*}$} \\
\hline Air conditioning & $\$ 1,176$ & \\
\hline Uninterruptible power supply & 802 & \\
\hline Generator & 1,280 & \\
\hline Network backbone & 705 & \\
\hline Internet connectivity & 20 & \\
\hline Router & 68 & \\
\hline Firewall & 409 & \\
\hline Inter-networking Ethernet switches & 177 & $\$ 4,637$ \\
\hline \multicolumn{3}{|l|}{ LABOR } \\
\hline \multicolumn{3}{|l|}{ Website } \\
\hline Content determination and updates & $\$ 16,619$ & \\
\hline System architecture & 18,302 & \\
\hline Programming & 36,525 & \\
\hline \multicolumn{3}{|l|}{ User support } \\
\hline Tier 1 (Project Manager) & 23,328 & \\
\hline Tier 2 (Intervention Director) & 33,239 & \\
\hline Tier 3 (Developer/programmer) & 10,957 & $\$ 138,970$ \\
\hline \multicolumn{3}{|l|}{ Interactive Voice Response (IVR) } \\
\hline Programming & $\$ 28,096$ & \\
\hline Technical support & 14,078 & $\$ 42,174$ \\
\hline \multicolumn{3}{|l|}{ Other } \\
\hline Project management & $\$ 16,619$ & $\$ 16,619$ \\
\hline Total Labor & & $\$ 202,400$ \\
\hline \multicolumn{3}{|l|}{ NON-LABOR } \\
\hline \multicolumn{3}{|l|}{ Website } \\
\hline \multicolumn{3}{|l|}{ Hardware } \\
\hline Web Farm Servers (Three) & $\$ 1,089$ & \\
\hline Backup Servers (Two) & 141 & \\
\hline SQL Database Server & 3,453 & \\
\hline SQL Reporting Server & 141 & \\
\hline Domain Control Servers (Two) & 121 & $\$ 4,945$ \\
\hline \multicolumn{3}{|l|}{ Software } \\
\hline SQL Server & $\$ 2,200$ & \\
\hline Mail server software & 6 & \\
\hline Windows Enterprise Server (Two) & 100 & $\$ 2,306$ \\
\hline \multicolumn{3}{|l|}{ Interactive Voice Response (IVR) } \\
\hline Equipment* & $\$ 1,713$ & \\
\hline
\end{tabular}




\begin{tabular}{|l|l|r|r|} 
Extended support (1.5 years) & & 6,513 & $\$ 8,226$ \\
\hline Additional Services & & & \\
\hline Internet service provider charges & & 1,305 & \\
\hline Data backup services & & 4,125 & $\$ 5,430$ \\
\hline Total Non-Labor & & & $\mathbf{\$ 2 0 , 9 0 6}$ \\
\hline Undiscounted & Total & & $\mathbf{\$ 2 2 3 , 3 0 6}$ \\
\hline & Per Participant & & $\mathbf{\$ 6 4 2}$ \\
\hline & Annual Per Participant & & $\mathbf{\$ 2 5 7}$ \\
\hline Discounted at 3\% annually & Total & & $\mathbf{\$ 2 1 4 , 8 7 9}$ \\
\hline & Per Participant & & $\mathbf{\$ 6 1 7}$ \\
\hline & Annual Per Participant & & $\mathbf{\$ 2 4 7}$ \\
\hline
\end{tabular}

Server, modem, dual telephony board, text-to-speech software, system software, training, licenses, and 1-year warranty 
Table 3

IT Intervention: Total costs--Development

\begin{tabular}{|c|c|c|}
\hline LABOR & & \\
\hline Needs Assessment & $\$ 41,520$ & \\
\hline Content Development & 114,018 & \\
\hline Design Specifications & 109,445 & \\
\hline Programming & 266,627 & \\
\hline Graphic Design & 28,449 & \\
\hline Usability Testing & 38,643 & \\
\hline Quality Assurance & 3,335 & \\
\hline Pilot Test & 12,784 & \\
\hline Project Management & 130,057 & \\
\hline Miscellaneous & 5,501 & $\$ 750,380$ \\
\hline \multicolumn{3}{|l|}{ NON-LABOR } \\
\hline \multicolumn{3}{|l|}{ Hardware (plus monthly maintenance charge) } \\
\hline \multicolumn{3}{|l|}{ Development \& Staging } \\
\hline Developers' PCs (prof. grade, including operating system) & $\$ 14$ & \\
\hline Development \& Staging Server & 63 & \\
\hline Exchange Server & 93 & $\$ 169$ \\
\hline \multicolumn{3}{|l|}{ Production } \\
\hline Web Farm Servers (Three) & $\$ 1,127$ & \\
\hline Backup Servers (Two) & 145 & \\
\hline SQL Database Server & 3,463 & \\
\hline SQL Reporting Server & 145 & \\
\hline Domain Control Servers (Two) & 125 & $\$ 5,005$ \\
\hline \multicolumn{3}{|l|}{ Software (requires Microsoft Office) } \\
\hline Visio Professional & $\$ 3$ & \\
\hline Visual Studio & 4 & \\
\hline Visual Sourcesafe & 3 & \\
\hline Adobe Creative Suite & 15 & \\
\hline SQL Server & 440 & \\
\hline Persits Mail Control & 3 & \\
\hline Windows Server 2003 Standard & 50 & \\
\hline Internet Information Services and .NET & 0 & $\$ 517$ \\
\hline \multicolumn{3}{|l|}{ Additional Services } \\
\hline Internet service provider charges & $\$ 1,566$ & \\
\hline Data backup services & 4,950 & \\
\hline Months 31-36 of incremental infrastructure & 195 & $\$ 6,711$ \\
\hline \multicolumn{3}{|l|}{ Interactive Voice Response (IVR) } \\
\hline LABOR & & \\
\hline
\end{tabular}




\begin{tabular}{|c|c|c|c|}
\hline Programming & & $\$ 43,830$ & \\
\hline Script and algorithm design & & 28,697 & \\
\hline Testing & & 19,943 & \\
\hline Technical support & & 21,962 & $\$ 114,432$ \\
\hline \multicolumn{4}{|l|}{ NONLABOR } \\
\hline Total system installation cost* & & $\$ 1,713$ & \\
\hline IVR extended support ( 2 years) & & 434 & $\$ 2,147$ \\
\hline \multicolumn{4}{|l|}{ Development (36 months) } \\
\hline \multirow[t]{3}{*}{ Undiscounted } & Total & & $\$ 879,362$ \\
\hline & Per Participant & & $\$ 2,527$ \\
\hline & Annual Per Participant & & $\$ 842$ \\
\hline \multirow[t]{3}{*}{ Discounted at $3 \%$ annually } & Total & & $\$ 839,949$ \\
\hline & Per Participant & & $\$ 2,414$ \\
\hline & Annual Per Participant & & $\$ 805$ \\
\hline \multicolumn{4}{|c|}{ Development + Implementation (66 months) } \\
\hline \multirow[t]{3}{*}{ Undiscounted } & Total & & $\$ 1,102,668$ \\
\hline & Per Participant & & $\$ 3,169$ \\
\hline & Annual Per Participant & & $\$ 576$ \\
\hline \multirow[t]{3}{*}{ Discounted at $3 \%$ annually } & Total & & $\$ 1,045,197$ \\
\hline & Per Participant & & $\$ 3,003$ \\
\hline & Annual Per Participant & & $\$ 546$ \\
\hline
\end{tabular}

